\title{
Biobriket Dari Limbah Abu Batu Bara Sisa Pembakaran PLTU Dan Serbuk Penggergajian Kayu dengan Perekat Kertas Bekas
}

\author{
Myson \\ Fakultas Teknik Universitas Batanghari Jambi \\ Correspondence email: myson@unbari.ac.id
}

\begin{abstract}
Abstrak. Penelitian ini bertujuan untuk mengurangi limbah dan mengolahnya menjadi briket sehingga menghasilkan energi yang bisa dimanfaatkan oleh masyarakat banyak. Bottom ash dari sisa pembakaran batu bara untuk PLTU, kertas bekas dari perkantoran dan Pendidikan serta serbuk penggergajian kayu di sepanjang pinggiran sungai Batanghari khusunya di seberang kota Jambi merupakan limbah yang akan dimanfaatkan. Tiga komposisi awal ditentukan untuk mendapatkan kalori yang dihasilkan dari briket yang dibuat. Dari hasil uji laboratorium diperoleh nilai kalor dalam rentang 2500 hingga $2800 \mathrm{kkal} / \mathrm{kg}$. Hasil ini belum memuaskan dan masih perlu perubahan komposisi antara serbuk gergaji, abu batu bara dan kertas bekas agar didapatkan nilai kalor yang sesuai dengan nilai kalor yang dihasilkan gas lpg.
\end{abstract}

Kata Kunci: Biobriket, limbah, panas

\begin{abstract}
This research aims to reduce waste and process it into briquettes so that it produces energy that can be utilized by many people. Bottom ash from the rest of coal burning for PLTU, used paper from offices and education activities and sawdust along the banks of the Batanghari river, especially across the city of Jambi, are waste that will be utilized. The three initial compositions are determined to obtain the calories produced from the briquettes made. From the laboratory test results, it is obtained that heating values are in the range of 2500 to $2800 \mathrm{kcal} / \mathrm{kg}$. These results are not satisfactory and still need to change the composition between sawdust, coal ash and waste paper in order to obtain a calorific value that corresponds to the calorific value produced by LPG gas.
\end{abstract}

Keywords: Biobriquette, waste, heat

\section{PENDAHULUAN}

Dalam kehidupan masyarakat modern seperti saat ini peran bahan bakar minyak dan gas menjadi sangat penting. Minyak dan gas saat ini merupakan kebutuhan pokok bagi masyarakat Desa maupun Kota. Untuk sebagian besar rumah tangga maupun sebagian pengusaha di Indonesia minyak dan gas menjadi kebutuhan utama. Karena begitu pentingnya, maka minyak dan gas diatur oleh pemerintah. Walaupun pemerintah sampai saat terus memberikan subsidi untuk lpg $3 \mathrm{~kg}$, namun hal ini merupakan suatu hal yang harus di atasi, karena subsidi pertanda ketidak sehatan ekonomi masyarakat.

Disisi lain, saat ini di sepanjang aliran sungai Batanghari masih banyak dijumpai tempat penggergajian kayu yang menghasilkan limbah utama berupa serbuk gergajian. Serbuk gergajian dalam kondisi kering sangat bisa terbakar. Saat ini serbuk gergajian tidaklah banyak diupayakan untuk mengatasi kebutuhan bahan bakar walau diketahui bahwa kayu merupakan salah satu bahan yang dapat dibakar.

Saat ini pemerintah terus menambah pembangkit listrik untuk memenuhi kebutuhan energy listrik masyarakat, industri dan transportasi. Transportasi masa depan akan memilih listrik sebagai energi utama untuk menggerakkan kendaraan, dan ini akan menjadi trend dunia tranportasi. Karena kebutuhan listrik yang sangat besar tersebut maka limbah yang dihasilkan juga sangat banyak. Pembangkit listrik tenaga uap (PLTU) membutuhkan batubara sebagai bahan bakarnya. Limbah yang akan dihasilkan berupa fly ash dan bottom ash. Menurut peraturan pemerintah fly ash ini harus ditangkap dan bahwa saat ini fly ash dan bottom ash merupakan limbah B3. Dan saat ini fly ash dan bottom ash juga cukup banyak di hasilkan di provinsi Jambi ini, karena ada beberapa PLTU yang telah beroperasi di provinsi Jambi.

Dari limbah di atas sebenarnya dapat di jadikan solusi untuk mengatasi kebutuhan masyarakat dan mengurangi subsidi pemerintah pada bahan bakar untuk masyarakat. Memang hal ini akan menghadapi kesulitan tersendiri yang diakibatkan oleh adanya kebijakan limbah B3. Solusi itu berupa briket bio yang akan menggantikan penggunaan lpg dimasyarakat maupun industri.

Salah satu tujuan penelitian ini adalah untuk mengubah limbah menjadi energi. Diupayakan hasil dari penelitian ini dapat menghasilkan produk yang berupa briket yang dapat dimanfaatkan oleh masyarakat.

\section{Serbuk Pengergajian}

Dari data statistik provinsi jambi tahun 2017 produksi kayu gelondongan provinsi Jambi mencapai $27.802 \mathrm{~m} 3$ dan dari kayu gelondongan tersebut menghasilkan kayu gergajian sebanyak $22.058 \mathrm{~m} 3$. Selisih antara kayu 
gelondongan dan produksi kayu gergajian merupakan limbah yang jumlahnya mencapai $5.744 \mathrm{~m} 3$. Jika $40 \%$ dari sisa gergajian adalah serbuk, maka akan dihasilkan $2.297 \mathrm{~m} 3$ serbuk gergajian dalam satu tahun. Hal ini tidak bisa dibiarkan terus karena limbah ini akan terus menumpuk dan menggunung yang pada akhirnya akan mengganggu kehidupan masyarakat sekitar.

\section{Bottom Ash}

Proses pembakaran batubara selain menghasilkan panas, juga menghasilkan limbah berupa fly ash dan bottom ash. Saat ini fly ash wajib di kelola sehingga tidak mencemari lingkungan. Sedangkan bottom ash yang ukuranya lebih besar dari butiran fly ash tertinggal di dasar atau bawah tungku pembakaran. Bottom ash jumlahnya tidak banyak, namun apabila dibiarkan di lingkungan, bisa mencemari lingkungan. Hasil penelitian menunjukkan bahwa secara fisik bottom ash dari reaktor gasifikasi Palimanan dapat diklasifikasikan menjadi dua jenis, yaitu bottom ash dry dan bottom ash slag. Secara kimia, komposisi abunya didominasi oleh $\mathrm{SiO}_{2}$ dan $\mathrm{Al}_{2} \mathrm{O}_{3}$ yang bisa dikaitkan dengan sifat pozzolan. Hasil analisis proksimat menunjukkan bahwa fixed carbon dari ash dry lebih tinggi yaitu 27,61 \% ( nilai kalori $3131 \mathrm{kal} / \mathrm{gram}$ ) sedangkan ash slag sebesar 0,74 \% (nilai kalori 63,4 kal/gram).

\section{Limbah kertas}

Sampai saat ini limbah kertas masih banyak dijumpai. Hal ini dikarenakan masih banyaknya kantor dan lembaga pendidikan yang masih menggunakan kertas sebagai pembuatan dokumen dan yang lain-lainnya. Program paperless ternyata masih sedikit diterapkan, khususnya di provinsi Jambi.

Sebenarnya pemerintah telah menuangkan program ini dalam beberapa undang-undang yaitu pada undangundang no 14 tahun 2008 tentang keterbukaan informasi publik dimana pada pasal 2 ayat 1 di sebutkan bahwa setiap informasi publik bersifat terbuka dan dapat diakses oleh pengguna informasi publik. Kemudian pada pasal 7 di sebutkan bahwa badan publik menyediakan informasi publik secara akurat, benar dan tidak menyesatkan.

Selanjutnya dalam undang-undang no 25 tahun 2009 tentang pelayanan publik di pasal 23 disebutkan dalam rangka pemberian informasi atas penyelenggaraan publik perlu diselenggarakan sistim informasi yang bersifat nasional.

Dalam undang-undang no 11 tahun 2008 tentang informasi dan transaksi elektronik (ITE) dijelaskan bahwa dokumen elektronik adalah semua informasi elektronik yang dibuat, diteruskan, dikirim dan diterima kemudian disimpan dalam bentuk analog, digital, elektromagnetik, optikal atau sejenisnya yang dapat dilihat atau ditampilkan atau di dengar melalui komputer. Ini merupakan dokumen yang diakui negara.

Untuk menjalankan undang-undang tersebut diatas hanya dapat dilakukan dengan sistim dokumen online yang artinya tidak menggunakan kertas atau paperless.

\section{Energi Kalor Pembakaran}

Kalor merupakan panas yang bisa berpindah dari benda yang memiliki kelebihan kalor menuju benda yang kekurangan kalor. Kalor biasanya dinyatakan dalam suhu. Dalam satuan internasional, kalor dinyatakan dengan Joule. Satuan lainnya dinyatakan dengan kalori. 1 kalori didefinisikan sebagai banyaknya kalor yang diperlukan untuk menaikan temperature air sebanyak $1 \mathrm{~kg}$ air sebesar $1^{\circ} \mathrm{C}$.

Kalor jenis adalah banyaknya kalor yang diserap atau diperlukan oleh 1 gram zat untuk menaikkan suhu sebesar $1^{\circ} \mathrm{C}$. Kalor jenis juga diartikan sebagai kemampuan suatu benda untuk melepas atau menerima kalor. Masing-masing benda mempunyai kalor jenis yang berbeda-beda. Satuan kalor jenis ialah $\mathrm{J} / \mathrm{kg}^{\circ} \mathrm{C}$.

\section{Analisa Kualitas Batu Bara}

Harga batu bara sangat tergantung pada kualitas, semakin baik kualitas maka akan semakin tinggi pula harganya. Itulah sebabnya kualitas batu bara yang telah ada harus selalu dijaga agar tidak terjadinya perbedaan kualitas terhadap kontrak yang telah disepakati dengan pembeli.

Kualitas batu bara terdiri dari beberapa parameter, yaitu Total Moisture (TM), Inherent Moisture (IM), Fixed Carbon (FC), Ash, Volatile Matter (VM), Total Sulfur (TS) dan Calorie Value (CV). Pada umumnya, terdapat dua metode analisa yang digunakan untuk mengetahui kualitas batu bara yaitu air-dried based (adb) dan as received (ar). Analisa air-dried base (adb) adalah analisa contoh batu bara yang dilakukan dalam keadaan kelembaban udara sekitarnya. Contoh batu bara akan didiamkan beberapa waktu sehingga kandungan moisture berkurang. Sedangkan analisa as receivied (ar) adalah analisa contoh batu bara yang langsung dilakukan ketika contoh tersebut diterima di laboratorium sehingga kandungan moisture saat pengambilan contoh batu bara sangat berpengaruh terhadap nilai kualitas.

Perbedaan mendasar pada kedua analisa ini dipengaruhi oleh Total Moisture (TM). Kandungan TM yang tinggi dapat menurunkan kualitas batu bara, terutama pada nilai Calorie Value (CV). Apabila nilai TM meningkat secara otomatis maka nilai kalori pun akan turun, sebaliknya apabila TM dapat dijaga atau diturunkan maka nilai CV akan relative stabil bahkan akan meningkat. 


\section{METODE}

Penelitian ini menggunakan metode eksperimen. Pembuatan briket dari kedua bahan limbah tersebut dengan menambah ketas bekas sebagai campuran tambahan dan juga sebagai perekat. Briket ini akan dibuat dengan komposisi yang direncanakan, dengan memperhitungkan nilai bakar yang akan didapat. Sebelumnya telah dilakukan analisa ketersediaan terhadap bahan baku pembuatan briket dan setelah briket siap untuk dibakar maka dilakukan pengujian dengan menggunakan bomb calorimeter. Data yang didapat merupakan data primer yang akan dianalisa untuk melihat sejauh mana efektifitas briket ini jika digunakan sebagai bahan bakar di rumah tangga. Desain rencana pembuatan biobriket berbentuk silinder ini dengan membuat komposisi bahan pembentuk biobriket tersebut.

\section{HASIL DAN PEMBAHASAN}

Pada saat penimbangan didapatkan data awal dari masing-masing bahan baku pembuatan biobriket ini per 200 $\mathrm{ml}$. Untuk bottom ash $155 \mathrm{grm} / 200 \mathrm{ml}$ dan untuk sawdust adalah $40 \mathrm{grm} / 200 \mathrm{ml}$.

Setelah dilakukan pengambilan data untuk pembuatan biobriket ini dengan komposisi yang direncanakan didapat data sebagai berikut :

Tabel 1. Komposisi Jumlah Sampel

\begin{tabular}{ccccc}
\hline Komposisi & Bottom ash & Saw dust & Pulp & Ket \\
\hline 1 & $15 \%$ & $35 \%$ & $50 \%$ & 5 sampel \\
3 & $15 \%$ & $30 \%$ & $55 \%$ & 5 sampel \\
\hline
\end{tabular}

Dari campuran tersebut setelah ditekan, didapatkan berat basah masing-masing komposisi.

Tabel 2. Berat Basah biobriket

\begin{tabular}{cccccc}
\hline Komposisi & \multicolumn{5}{c}{ Berat Basah (grm) } \\
\hline 1 & 125 & 125 & 125 & 140 & 140 \\
3 & 120 & 120 & 120 & 120 & 120 \\
\end{tabular}

Setelah dilakukan pengeringan dengan cara di jemur di bawah terik sinar matahari selama lebih kurang 3 hari maka didapatkan berat kering seperti pada table 3 dibawah ini.

Tabel 3. Berat Kering biobriket

\begin{tabular}{cccccc}
\hline Komposisi & \multicolumn{5}{c}{ Berat Kering (grm) } \\
\hline 1 & 50 & 65 & 65 & 65 & 65 \\
3 & 65 & 65 & 65 & 65 & 65 \\
\end{tabular}

Dari proses pengeringan dijemur dibawah terik sinar matahari selama 3 hari menghasilkan biobriket kering yang sangat baik.

Dari Analisa yang dilakukan pada Lembaga uji yang tersertifikasi Sucofindo cabang Jambi dengan menggunakan bomb calorimeter didapatkan data sebagai berikut.

Tabel 5. Hasil Analisa Laboratorium (PT. Sucofindo)

\begin{tabular}{|c|c|c|c|c|c|c|c|c|c|c|c|}
\hline \multirow[t]{4}{*}{ Sample } & \multirow{4}{*}{$\begin{array}{r}\text { Weight } \\
\text { kg }\end{array}$} & \multicolumn{10}{|c|}{ Report } \\
\hline & & \multicolumn{3}{|c|}{ AR } & \multicolumn{3}{|c|}{ ADB } & \multicolumn{2}{|c|}{ AR } & \multicolumn{2}{|c|}{ DB } \\
\hline & & ADL & RM & TM & IM & TS & $\mathrm{CV}$ & $\mathrm{TS}$ & $\mathrm{CV}$ & $\mathrm{TS}$ & $\mathrm{CV}$ \\
\hline & & $\%$ & $\%$ & $\%$ & $\%$ & $\%$ & Kcal/kg & $\%$ & Kcal/kg & $\%$ & Kcal/kg \\
\hline 1 & 0,31 & 3,33 & 2,50 & 8,83 & 4,72 & 0,12 & 2161 & 0,12 & 2136 & 0,13 & 2268 \\
\hline 2 & 0,29 & 3,57 & 2,07 & 5,64 & 4,32 & 0,12 & 2187 & 0,12 & 2156 & 0,12 & 2285 \\
\hline 3 & 0,26 & 4,00 & 2,27 & 6,27 & 4,66 & 0,13 & 2464 & 0,13 & 2423 & 0,14 & 2585 \\
\hline
\end{tabular}

\section{As Received (AR)}

Dari hasil Analisa yang dilakukan oleh sucofindo didapatkan hasil bahwa AR (as received) untuk sampel 1 memiliki TM (total moisture) yang masih tinggi yaitu berkisar 8,83 \% dan nilai kalor yang didapat adalah sebesar $2136 \mathrm{Kcal} / \mathrm{kg}$. Hal ini menunjukan bahwa untuk sampel 1 pada saat akan diuji tanpa perlakuan menunjukan masih memiliki kandungan air yang cukup tinggi sebesar $8,83 \%$, sehingga nilai kalornya hanya sebesar $2136 \mathrm{Kcal} / \mathrm{kg}$ dengan kandungan sulfur sebesar $0,12 \%$. 
Untuk sampel 2 ternyata juga memiliki kandungan air yang masih tinggi yaitu 5,64\%. Sampel 2 ini memiliki TM yang lebih rendah dari sampel 1 . Untuk nilai kalornya adalah $2156 \mathrm{Kcal} / \mathrm{kg}$, lebih tinggi dibandingkan dengan sampel 1dengan kandungan sulfurnya sebesar $0,12 \%$.

Untuk sampel 3 dengan komposisi yang telah ditetapkan ternyata mengalami peningkatan nilai kandungan airnya dibandingkan dengan sampel 2 namun tetap lebih rendah dari sampel 1. Nilai Total moisture pada sampel 3 ini adalah sebesar 6,27\% dan nilai kalori sebesar $2423 \mathrm{Kcal} / \mathrm{kg}$ dengan kandungan sufur sebesar 0,13\%.

\section{Air-Dried Base (ADB)}

Uji sampel pada kondisi air-dried base (ADB) dimana sampel mengalami perlakuan yaitu di diamkan beberapa saat pada kondisi ruang uji yang di standarkan. Hasil uji air-dried base untuk sampel 1 didapatkan inhernt moisture (IM) yaitu kandungan air yang masih terdapat pada briket tersebut sebesar 4,72\% dengan nilai kalori sebesar 2268 $\mathrm{Kcal} / \mathrm{kg}$. Sedangkan sulfur yang terkandung sebesar $0,13 \%$.

Untuk sampel 2 inherent moisture adalah sebesar 4,32\% dan nilai kalori sebesar $2285 \mathrm{Kcal} / \mathrm{kg}$ dengan kandungan sulfur sebesar $0,12 \%$

Untuk sampel 3 inherent moisture yang terkandung adalah sebesar 4,66\% dengan nilai kalori sebesar 2585 $\mathrm{Kcal} / \mathrm{kg}$.

\section{SIMPULAN}

Dari hasil uji yang diperoleh dapat disimpulkan bahwa biobriket ini masih rendah nilai kalornya. Ini dapat dilihat dari setiap komposisi sampel tidak ada yang melebihi nilai kalor dari kayu bakar berkisar $3500 \mathrm{Kcal} / \mathrm{kg}$.

Pemanfaatan biobriket ini dapat mengurangi limbah bottom ash berkisar antara 10\% hingga 15\% sedangkan saw dust dapat dikurangi 30\% hingga 35\%. Sedangkan limbah kertas bekas dapat dikurangi hingga 50\% hingga 60\%.

Bahwa inhrent moisture merupakan komponen yang akan menurunkan nilai kalori dari biobriket, makin besar persentasenya maka makin besar pula tingkat penurunanya.

Terdapat kandungan sulfur sebesar $0,12 \%$ hingga $0,13 \%$ pada saat as received dan $0,12 \%$ hingga $0,14 \%$ pada air-dried base. Sulfur ini berasal dari bottom ash yang dihasilkan dari pembakaran batu bara lokal yang digunakan PLTU tempat bottom ash berasal.

\section{DAFTAR PUSTAKA}

Aji, Setyo.B dan Anjar. 2009. The Role Of a Coal Gasification Fly Ash as Clay Addive in Building Ceramic. Journal of the European Ceramic Sosiety 26 (2006) 3783-3787.

Hasan Basri, Dr.Ir, 2007, ' Teknik Kogenerasi (bahan kuliah),PPs Unsri, Palembang.

Moran, J Michael \& Shapiri N Howard,1999,"Fundamental Engineering Thermodynamics”, fourth edition, Jhon Wiley

Nelly, Komang Sundari 2010. Pengaruh Perlakuan Suhu Bakar Pada Massa Bodi Keramik Stone Kode BL 1 Terhadap Parameter Penyusutan dan Peresapan Air. Bali: Skripsi.

Prayitno, Dody. Teknologi Rekayasa Material. Jakarta: 2010

Reynold, C William \& Perkins C Henry, 1977,"Termodinamika Teknik”, Alih Bahasa Filino Harahap, 1982, Erlangga

Roger Kinsky M.Eng,Sc.,B.E.,B.Sc, 'Applied Heat', An Introduction to thermodynamics, Second edition.

Sheth, P.N and Babu, B.V.2006."Kinetic Modeling of the Pyrolysis of Biomass, Procedings of National Conference on Environmental Conservation", 453-458

Suasmoro, Dr. 2000. Fisika Keramik. Surabaya. Jurusan Fisika FMIPA ITS.

Subiyanto, Hari Subowo. 2003. Pengaruh Temperatur Sintering terhadap Sifat Mekanik Keramik Insulator Listrik. Surabaya: ITS.

Surdia, Tata dan Kenji Chijiwa. Pengetahuan Bahan Teknik. Jakarta: Pradya Paramita, 2006.

Teodora Deac, Tutunaru, L.F, Ferenc Gaspar.,2016,'Environmental Impact of Sawdust Briquettes Use- Experimental Approach".Technical University of Cluj-Napoca. Faculty of Mechanical Engineering: Romania.

Van Vlack, Lawrence. H. 2004. Elemen - Elemen Ilmu Dan Rekayasa Material. Jakarta: Erlangga Adrian Bejan, 1988, 'Advanced Engineering Thermodynamics', Jhon Wiley\&son.Inc

Zul Fahmi 1, Rr. Harminuke Eko Handayani 2, Syarifudin,” PENGARUH PENGGUNAAN BOTTOM ASH DRY DAN SLAG LIMBAH GASIFIKASI BATUBARA PADA PEMBUATAN BATAKO TERHADAP KUAT TEKAN", JP Vol.1 No.2 Februari 2017 ISSN 2549-1008 